\title{
Comparison of postoperative outcomes between bilateral axillo-breast approach-robotic thyroidectomy and transoral robotic thyroidectomy
}

\author{
Sun Moon Yang ${ }^{1 \#}$, Won Seo Park ${ }^{2 \#}$, Ji Young You ${ }^{1}$, Da Won Park ${ }^{1}$, Hannah Lois Kangleon-Tan ${ }^{3}$, Hong \\ Kyu Kim ${ }^{4}$, Gianlorenzo Dionigi ${ }^{5}$, Hoon Yub Kim ${ }^{1}$, Ralph P. Tufano ${ }^{6}$ \\ ${ }^{1}$ Department of Surgery, KUMC Thyroid Center, Korea University Hospital, Korea University College of Medicine, Seoul, Korea; ${ }^{2}$ Department \\ of Surgery, Kyung Hee University School of Medicine, Seoul, Korea; ${ }^{3}$ Chong Hua Hospital General Surgery Department, Cebu City, Philippines; \\ ${ }^{4}$ Department of Surgery, Seoul National University Hospital, Seoul, Korea; ${ }^{5}$ Division for Endocrine and Minimal Invasive Surgery, Department of \\ Human Pathology in Adulthood and Childhood "G.Barresi', University Hospital “G.Martino”, University of Messina, Messina, Italy; ${ }^{6}$ Department \\ of Otolaryngology - Head and Neck Surgery, The Johns Hopkins University School of Medicine, Baltimore, Maryland, USA \\ Contributions: (I) Conception and design: HY Kim; (II) Administrative support: WS Park; (III) Provision of study materials or patients: DW Park, HK \\ Kim; (IV) Collection and assembly of data: SM Yang; (V) Data analysis and interpretation: SM Yang, JY You, HL Kangleon-Tan; (VI) Manuscript \\ writing: All authors; (VII) Final approval of manuscript: All authors. \\ \#These authors contributed equally to this work. \\ Correspondence to: Hoon Yub Kim, MD, PhD, FACS. Department of Surgery, Korea University College of Medicine, Inchon-ro 73, Seongbuk-gu, \\ Seoul 02841, Korea. Email: hoonyubkim@korea.ac.kr.
}

Background: The use of robotic systems for thyroidectomy has increased as it enables more diverse approaches than the conventional open method. The aim of this study was to compare the clinical outcomes of Transoral Robotic Thyroidectomy (TORT) and Bilateral Axillo-Breast Approach-Robotic Thyroidectomy (BABA-RT).

Methods: This study was designed as a retrospective study. The included patients who underwent surgery by BABA-RT or TORT approach in our facility between 2008 and 2018. All surgeries were performed by one surgeon. Total thyroidectomy with central node dissection (CND) was performed only if tumors were $>4$ $\mathrm{cm}$ and had extrathyroidal extension, clinically apparent lymph node or distant metastases. In all other cases, lobectomy \pm CND was performed.

Results: The group treated with TORT comprised 248 patients and the group that underwent BABART had 316 patients. The number of retrieved lymph node (LN) was higher in the TORT group (4.9 \pm 4.4 vs. 4.2 $\pm 4.9 ; \mathrm{P}=0.01)$. There were no significant differences between the TORT and BABA-RT groups in concerns to the location of the tumor. Postoperative hospital stay was also shorter in the TORT group when

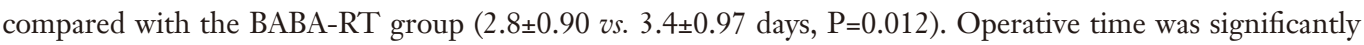
shorter in the TORT group $(204.11 \pm 40.19$ vs. $243.78 \pm 57.16 \mathrm{~min}, \mathrm{P}<0.01)$

Conclusions: When comparing a total of 248 patients treated with TORT versus 316 with BABA-RT. TORT not only has advantages in better cosmetic outcomes with minimized postoperative scars, but also shows comparable, or even superior, surgical outcomes with shorter operation time than the BABA-RT procedure.

Keywords: Bilateral axillo-breast approach-robotic thyroidectomy (BABA-RT); transoral robotic thyroidectomy; robotic thyroidectomy; transoral thyroidectomy; bilateral axillo-breast approach thyroidectomy; thyroidectomy

Submitted Apr 23, 2020. Accepted for publication Oct 21, 2020.

doi: $10.21037 /$ gs-20-468

View this article at: http://dx.doi.org/10.21037/gs-20-468 


\section{Introduction}

Many surgical approaches have been developed and studied to minimize neck scarring during thyroid surgery. Consequently, minimally invasive thyroid surgery has been developed. Endoscopic techniques for the surgical treatment of parathyroid and thyroid glands were first reported by Gagner and Hüscher et al. respectively $(1,2)$. These authors introduced several forms of endoscopic thyroid surgeries using axillary, breast, anterior thoracic and cervical approaches.

Ever since the onset of endoscopic surgery, various techniques of endoscopic thyroid surgery have been introduced worldwide. Along with these developments, several studies assessed the safety and feasibility of these new methods. In some papers, they have demonstrated the validity and safety of bilateral axillo-breast approach (BABA)-thyroidectomy procedure compared to open surgery (3).

Until today, many surgeons performed thyroidectomy surgery using BABA procedure. The surgical method developed and moved to the natural orifice transluminal endoscopic surgery method. This technique of natural orifice transluminal endoscopic surgery applied to thyroidectomy through an intraoral approach has been performed in a porcine model and human cadavers (4-6).

There are two methods of transoral natural orifice transluminal endoscopic thyroidectomy. One approach is through the sublingual thyroid access and the other is through the oral vestibular. The trans-sublingual method is not well used because of the relatively large number of complications, and currently the trans-vestibular approach is widely used $(7,8)$.

The transoral approach has been recently adopted for minimally invasive thyroid surgery and since then, it has become popular (9). Transoral robotic thyroidectomy (TORT) uses three ports on the lower lip and one additional axillary port in the right axilla (10).

The use of robotic systems for thyroidectomy has increased as it enables more diverse approaches than the conventional open method. After all, the robotic system provides better surgical field and allows multi-articulated movement (11). We have reported the feasibility of TORT in our previous study (12), but our study did not compare the clinical outcomes of TORT with BABA-robotic thyroidectomy (RT). The aim of this study was to compare the clinical outcomes of TORT and BABA-RT (Video 1). We present the following article/case in accordance with the STROBE reporting checklist (available at http://dx.doi. org/10.21037/gs-20-468).

\section{Methods}

\section{Patients}

The study protocol was approved by the Institutional Review Board of Korea University Hospital (approval number: 2017AN0077) and was performed in accordance with the ethical standards of the Declaration of Helsinki (as revised in 2013). All patients gave their informed consent prior to their inclusion in the study. BABA-RT surgery was performed between 2008 and 2016 and TORT is in place since 2012. This study included patients who underwent surgery by BABA-RT or TORT approach in our facility between 2008 and 2018. All surgeries were performed by one surgeon (H.Y. Kim). According to American Thyroid Association (ATA) guidelines 2015, total thyroidectomy with central node dissection (CND) was performed only if tumors were $>4 \mathrm{~cm}$ and had extrathyroidal extension, clinically apparent lymph node or distant metastases. In all other cases, lobectomy \pm CND was performed.

\section{Preoperative preparation}

All patients underwent prophylactic antibiotics before surgery and preoperatively vocal cord status was assessed by indirect laryngoscopy. In BABA-RT cases, additional breast mammography and ultrasound were used to confirm breast tissue has some problem before surgery. In TORT cases, all patients underwent treatment and scaling at the dentist prior to surgery, and gentle cleaning with chlorhexidine gluconate solution was maintained for 1 week prior to surgery.

\section{Operative procedures of TORT}

The TORT procedure has been described in detail previously (12). TORT was performed using a camera port with one $12 \mathrm{~mm}$ trocar, and two $5 \mathrm{~mm}$ trocar on the lower lip. An additional $8-\mathrm{mm}$ port was used as a working port via the right axilla. This axillary port was used for specimen removal and to insert drain post-surgery. Epinephrine dilution $(1: 200,000)$ was injected in the jaw and lower neck and flapped through the midline incision. The upper and lower margins of the flap were the thyroid cartilage and sternal notch, with the lateral margins being the medial 
Table 1 Patient characteristics of TORT and BABA-RT

\begin{tabular}{lcc}
\hline Variables & TORT $(\mathrm{n}=248)$ & BABA-RT $(\mathrm{n}=316)$ \\
\hline Mean age, years & $40.62 \pm 10.9$ & $40.03 \pm 9.7$ \\
Gender & & 0.504 \\
Male & $42(16.9 \%)$ & $30(9.5 \%)$ \\
Female & $206(83.1 \%)$ & $286(90.5 \%)$ \\
Body mass index, mean \pm SD $\left(\mathrm{kg} / \mathrm{m}^{2}\right)$ & $23.27 \pm 3.81$ & $23.06 \pm 3.7$ \\
Tumor size & $0.96 \pm 0.95$ & $0.86 \pm 0.91$ \\
Tumor location & & 0.502 \\
Right lobe & 120 & 141 \\
Left lobe & 108 & 114 \\
Isthmus & 8 & 7 \\
Both lobes & 12 & 54 \\
\hline
\end{tabular}

TORT, transoral robotic thyroidectomy; BABA-RT, bilateral axillo-breast approach- robotic thyroidectomy; SD, standard deviation.

border of the sternocleidomastoid muscle of either side.

\section{Outcome evaluation}

Postoperative pain was scored using a visual analog scale (VAS) ranging from 0 (no pain) to 10 (worst pain). A routine indirect laryngoscopic examination was performed immediately after surgery. In this study, recurrent laryngeal nerve (RLN) palsy was defined as transient when vocal cord movements recovered within 6 months. Hypoparathyroidism was defined when the parathyroid hormone (PTH) level (normal range: PTH $>8 \mathrm{pg} / \mathrm{mL}$ ) and calcium level were below the normal range with an ongoing requirement for oral calcium supplement. Hypoparathyroidism was defined as permanent when it lasted beyond 6 months after surgery.

\section{Statistical analysis}

Results were analyzed with SPSS version 22 (SPSS, Inc. Chicago, IL, USA). Continuous variables and categorical variables were expressed, respectively, as mean and standard deviation, and frequency. Comparisons within groups were performed using Mann-Whitney, Fisher's exact or Chi-square test according to the sample size. A statistical difference was considered significant when $\mathrm{P}$ value was less than 0.05 .

\section{Results}

A total of 564 patients were included in this study. The group treated with TORT comprised 248 patients and the group that underwent BABA-RT had 316 patients. The characteristics of patients are described in Table 1. There was no significant difference between the TORT and the BABA-RT group concerning the mean age $(40.62 \pm 10.9$ vs. $40.03 \pm 9.7$ years; $\mathrm{P}=0.504)$, body mass index $(23.27 \pm 3.81$ vs. $\left.23.06 \pm 3.7 \mathrm{~kg} / \mathrm{m}^{2} ; \mathrm{P}=0.502\right)$. There was a difference in gender (male/female: 42/206 vs. 30/286; $\mathrm{P}=0.009$ ) between the two groups. This is probably thought to be due to men in our population placing a greater emphasis in cosmetic importance in recent times, causing them to opt for TORT.

The pathologic results are shown in Table 2. Pathologic outcomes differ from malignant to benign tumors in both groups [malignant $90.3 \%$, benign $9.7 \%$ (TORT) vs. malignant $97.8 \%$, benign $2.2 \%$ (BABA-RT); $\mathrm{P}<0.01$ ]. It is thought that the ratio of benign tumors in the TORT group is higher due to the fact that most thyroid surgeries are done by a robot at our hospital. The number of retrieved lymph node $(\mathrm{LN})$ was higher in the TORT group $(4.9 \pm 4.4$ vs. 4.2 \pm 4.9; $\mathrm{P}=0.01)$. There were no significant differences between the TROT and BABA-RT groups in concerns to the location of the tumor.

Postoperative pain was significantly lower on day 0 and day 1 after TORT surgery. Postoperative hospital stay was also shorter in the TORT group when compared with the 
Table 2 Pathologic results of TORT and BABA-RT

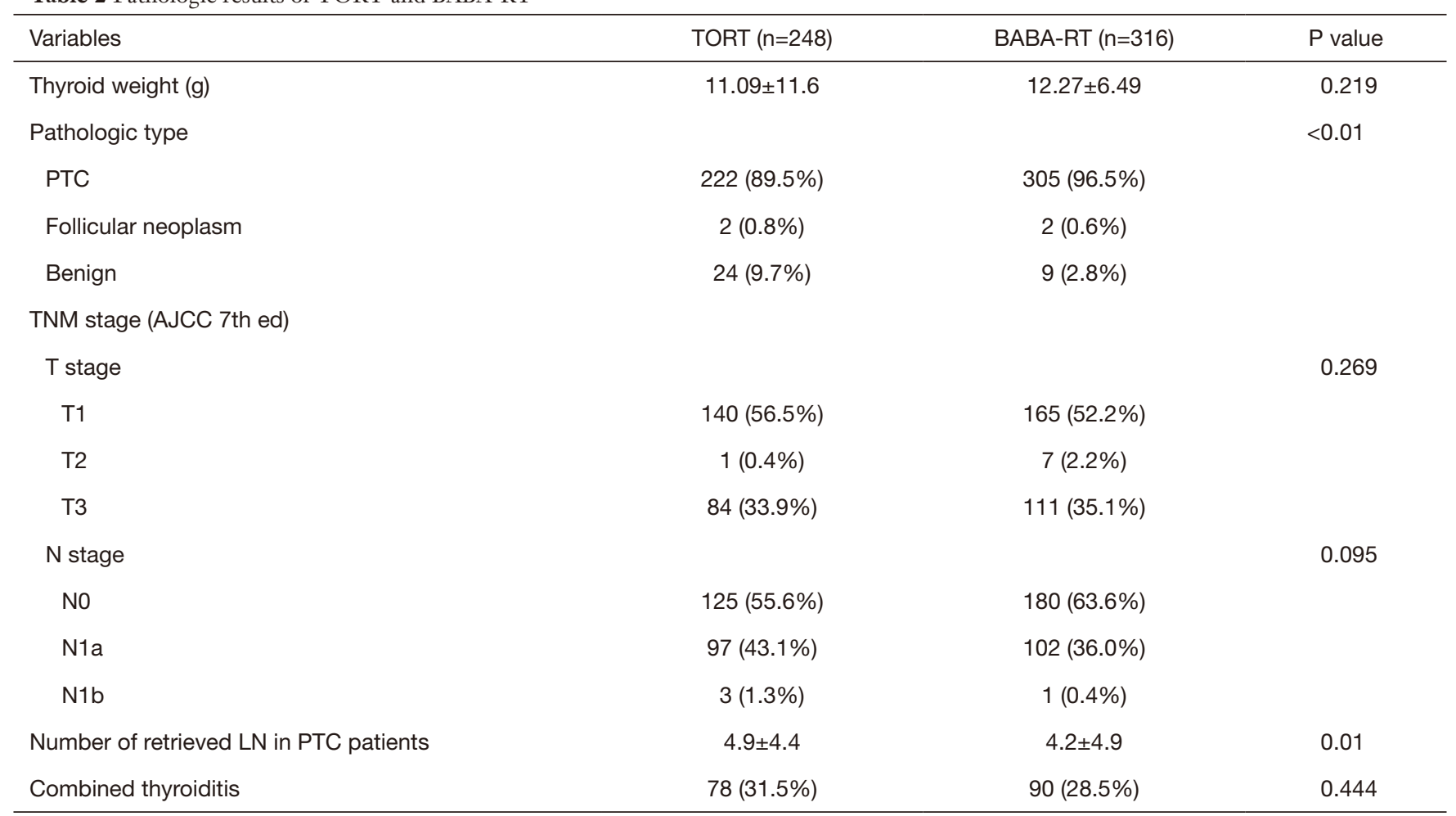

TORT, transoral robotic thyroidectomy; BABA-RT, bilateral axillo-breast approach- robotic thyroidectomy; PTC, papillary thyroid carcinoma; AJCC, American Joint Committee on Cancer; LN, lymph nodes.

BABA-RT group $(2.8 \pm 0.90$ vs. $3.4 \pm 0.97$ days, $\mathrm{P}=0.012)$. Operative time was significantly shorter in the TORT group $(204.11 \pm 40.19$ vs. $243.78 \pm 57.16 \mathrm{~min}, \mathrm{P}<0.01)$, but this is likely to be influenced by the recent trend toward lobectomy with thyroid surgery. The extent of surgery, especially lobectomy, was also significantly higher in the TORT group than BABA-RT group (Table 3).

Among 248 TORT patients, there was one case of bleeding and one patient with chyle leakage for postoperative complications. Both of the patients underwent reoperation and were discharged from the hospital without further events. There were 3 postoperative temporary vocal cord palsy, and all 3 patients recovered within 3 months from the temporary symptoms. In 315 patients with BABART, there were 7 cases of postoperative seroma. There were also 8 cases of vocal cord palsy in the BABA-RT group (3.3\%), which was more than that of the TORT group (1.2\%). For postoperative transient hypoparathyroidism, the TORT group had occurrence rate of $7.1 \%$ while the BABA-RT group had 16\% occurrence rate. Furthermore, there was one permanent hypoparathyroidism case which did not show recovery in the BABA-RT group. On the other hand, there were few TORT-specific complications to consider. There were 2 cases of zygomatic bruising, 1 case of chin flap perforation, 2 cases of oral commissure tearing, and 2 cases of dimpling on the chin in the TORT group (Table 4). It is important to note that these complications mostly occurred during the initial learning curve period of TORT. Hence, for surgeons newly starting TORT, they should pay extra caution with close monitoring to prevent these TORT-specific complications until the experience accumulates.

\section{Discussion}

This study showed that the total surgical outcome of TORT was equivalent to that of BABA-RT. The TORT group had many advantages such as, better outcome for retrieved LNs in patients with papillary thyroid carcinoma, decreased postoperative pain, hospital stay, operation time, and postoperative complications of seroma.

Transoral thyroidectomy procedure is less invasive and relatively safe than other surgical procedures (13-15). It does not require a flap on any part of the body other than 
Table 3 Comparison of Postoperative surgical outcome between TORT and BABA-RT

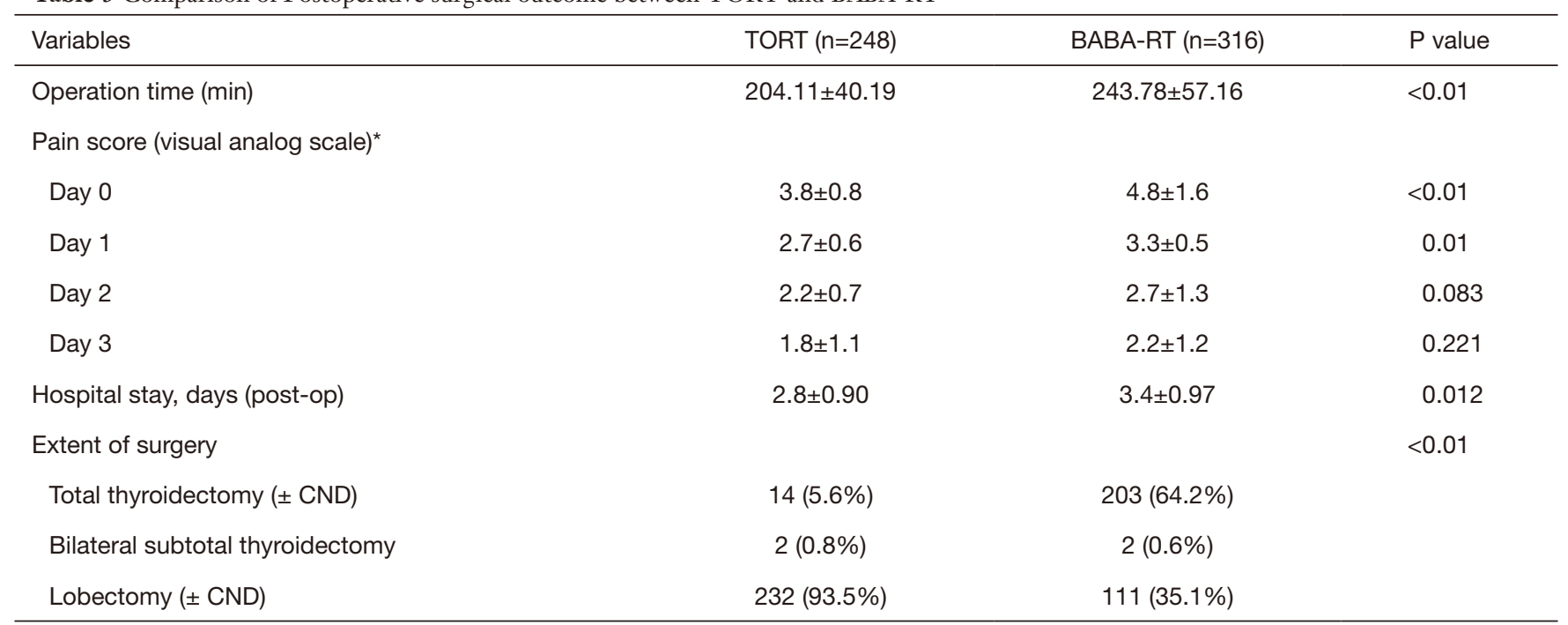

*, visual analog scale ranges 0 (no pain) to 10 (worst pain). TORT, transoral robotic thyroidectomy; BABA-RT, bilateral axillo-breast approach- robotic thyroidectomy; CND, Central node dissection.

Table 4 Comparison of postoperative surgical complications between TORT and BABA-RT

\begin{tabular}{|c|c|c|c|}
\hline Variables & TORT $(n=248)$ & BABA-RT $(n=316)$ & $P$ value \\
\hline Bleeding & $1(0.4 \%)$ & $0(0 \%)$ & N/A \\
\hline Surgical site infection & $0(0 \%)$ & $0(0 \%)$ & $\mathrm{N} / \mathrm{A}$ \\
\hline Seroma collection & $0(0 \%)$ & $7(2.2 \%)$ & $\mathrm{N} / \mathrm{A}$ \\
\hline \multicolumn{4}{|l|}{ Vocal cord palsy } \\
\hline Transient & $3(1.2 \%)$ & $8(2.5 \%)$ & 0.01 \\
\hline Permanent & $0(0 \%)$ & $0(0 \%)$ & N/A \\
\hline \multicolumn{4}{|l|}{ Hypoparathyroidism } \\
\hline \multicolumn{4}{|l|}{ TORT-specific complications } \\
\hline Mental nerve injury & $9(3.6 \%)$ & & \\
\hline Zygomatic bruising & $2(0.8 \%)$ & & \\
\hline Chin flap perforation & $1(0.4 \%)$ & & \\
\hline Oral commissure tearing & $2(0.8 \%)$ & & \\
\hline Dimpling on the chin & $2(0.8 \%)$ & & \\
\hline
\end{tabular}

TORT, transoral robotic thyroidectomy; BABA-RT, bilateral axillo-breast approach-robotic thyroidectomy. 
the anterior neck, resulting in a smaller flap dissection area than BABA-RT, and a lower complication rate. In addition, TORT results in no other scars than a small incision in the axillary area, so patient satisfaction after surgery is high. TORT has been tried with cosmetic advantages (16), and postoperatively it brings many advantages such as voice outcome, postoperative time and pain reduction. It seems to be a more ideal procedure in a high-tech era. Many surgeons have attempted trans-oral surgery on animals, cadavers, and humans $(4,7,17,18)$. However, this procedure requires a lot of practice because it can cause complications of mental nerve injury, numbness of the chin and lower lip.

We have previously published a comparison of 50 cases of TORT and BABA-RT (19). The same results were obtained with regard to the reduction in operation time, hospital stay, and pain score. Unlike previous papers, as the number of cases increases, the results of postoperative complication can be compared in both groups. When comparing TORT and BABA-RT approaches, TORT had a significantly lower postoperative transient vocal cord palsy and transient hypoparathyroidism, but also increased complications of initial learning period. There was a statistically significant difference in the total number of thyroidectomies between both groups. This was due to a change in the guidelines for thyroid surgery, reducing the total number of thyroidectomies. Another difference was the number of retrieved LNs. There was a relatively high difference in TORT, since this procedure is performed in a head-to-foot operative position meaning that the operation is more delicate due to a more comfortable posture and view.

The strength of this study is the relative small selection bias since there is a large number of patients treated by a single surgeon and, BABA-RT and TORT are collecting and comparing data continuously. On the other hand, the limitation is the use of a single surgeon. Consequently, experience increased along with the number of cases, which could cause bias. Second, the follow-up period of TORT was short, and the oncologic outcome was not observed for a long time. Third, compared to all patients undergoing TORT and BABA surgery, the ratio between lobectomy and total thyroidectomy is different. We want to argue through this paper is that TORT is not bad compared to the previous BABA surgery method. Finally, statistically, there were significant values in days of hospital stays and the number of retrieved LNs, but the significant values were insignificant, it can think that there is no significant difference between the two groups in clinically. This paper is divided into different periods according to the change of operation method according to the times. It is not a randomized study, but it is free from selection bias because the data were collected consecutively and we used whole data without omission.

In conclusion, when comparing a total of 248 patients treated with TORT versus 316 with BABA-RT, TORT not only has advantages in better cosmetic outcomes with minimized postoperative scars, but also shows comparable, or even superior, surgical outcomes with shorter operation time than the BABA-RT procedure.

\section{Acknowledgments}

Funding: This work was supported by a Korea University grant (K1813031).

\section{Footnote}

Reporting Checklist: The authors have completed the STROBE reporting checklist. Available at http://dx.doi. org/10.21037/gs-20-468

Data Sharing Statement: Available at http://dx.doi. org/10.21037/gs-20-468

Peer Review File: Available at http://dx.doi.org/10.21037/gs$20-468$

Conflicts of Interest: All authors have completed the ICMJE uniform disclosure form (available at http://dx.doi. org/10.21037/gs-20-468). RPT serves as an unpaid editorial board member of Gland Surgery from September 2020 to August 2022. Dr. Kim reports grants from Korea university grant (K1813031), during the conduct of the study and is a consultant for Medtronic. The other authors have no conflicts of interest to declare.

Ethical Statement: The authors are accountable for all aspects of the work in ensuring that questions related to the accuracy or integrity of any part of the work are appropriately investigated and resolved. The study protocol was approved by the Institutional Review Board of Korea University Hospital (approval number: 2017AN0077) and was performed in accordance with the ethical standards of the Declaration of Helsinki (as revised in 2013). All patients gave their informed consent prior to their inclusion in the study. 
Open Access Statement: This is an Open Access article distributed in accordance with the Creative Commons Attribution-NonCommercial-NoDerivs 4.0 International License (CC BY-NC-ND 4.0), which permits the noncommercial replication and distribution of the article with the strict proviso that no changes or edits are made and the original work is properly cited (including links to both the formal publication through the relevant DOI and the license). See: https://creativecommons.org/licenses/by-nc-nd/4.0/.

\section{References}

1. Gagner M. Endoscopic subtotal parathyroidectomy in patients with primary hyperparathyroidism. Br J Surg 1996;83:875.

2. Hüscher CS, Chiodini S, Napolitano C, et al. Endoscopic right thyroid lobectomy. Surg Endosc 1997;11:877.

3. Chung YS, Choe JH, Kang KH, et al. Endoscopic thyroidectomy for thyroid malignancies: comparison with conventional open thyroidectomy. World J Surg 2007;31:2302-6; discussion 7-8.

4. Witzel K, von Rahden BH, Kaminski C, et al. Transoral access for endoscopic thyroid resection. Surg Endosc 2008;22:1871-5.

5. Benhidjeb T, Wilhelm T, Harlaar J, et al. Natural orifice surgery on thyroid gland: totally transoral video-assisted thyroidectomy (TOVAT): report of first experimental results of a new surgical method. Surg Endosc 2009;23:1119-20.

6. Karakas E, Steinfeldt T, Gockel A, et al. Transoral thyroid and parathyroid surgery--development of a new transoral technique. Surgery 2011;150:108-15.

7. Wilhelm T, Metzig A. Endoscopic minimally invasive thyroidectomy (eMIT): a prospective proof-of-concept study in humans. World J Surg 2011;35:543-51.

8. Benhidjeb T, Witzel K, Stark M, et al. Transoral thyroid and parathyroid surgery: still experimental! Surg Endosc

Cite this article as: Yang SM, Park WS, You JY, Park DW, Kangleon-Tan HL, Kim HK, Dionigi G, Kim HY, Tufano RP. Comparison of postoperative outcomes between bilateral axillobreast approach-robotic thyroidectomy and transoral robotic thyroidectomy. Gland Surg 2020;9(6):1998-2004. doi: 10.21037/ gs-20-468
2011;25:2411-3.

9. Dionigi G, Bacuzzi A, Lavazza M, et al. Transoral endoscopic thyroidectomy via vestibular approach: operative steps and video. Gland Surg 2016;5:625-7.

10. Richmon JD, Kim HY. Transoral robotic thyroidectomy (TORT): procedures and outcomes. Gland Surg 2017;6:285-9.

11. Kang SW, Jeong JJ, Yun JS, et al. Robot-assisted endoscopic surgery for thyroid cancer: experience with the first 100 patients. Surg Endosc 2009;23:2399-406.

12. Kim HY, Chai YJ, Dionigi G, et al. Transoral robotic thyroidectomy: lessons learned from an initial consecutive series of 24 patients. Surg Endosc 2018;32:688-94.

13. Nakajo A, Arima H, Hirata M, et al. Trans-Oral VideoAssisted Neck Surgery (TOVANS). A new transoral technique of endoscopic thyroidectomy with gasless premandible approach. Surg Endosc 2013;27:1105-10.

14. Wang C, Zhai H, Liu W, et al. Thyroidectomy: a novel endoscopic oral vestibular approach. Surgery 2014;155:33-8.

15. Anuwong A. Transoral Endoscopic Thyroidectomy Vestibular Approach: A Series of the First 60 Human Cases. World J Surg 2016;40:491-7.

16. Clark JH, Kim HY, Richmon JD. Transoral robotic thyroid surgery. Gland Surg 2015;4:429-34.

17. Richmon JD, Holsinger FC, Kandil E, et al. Transoral robotic-assisted thyroidectomy with central neck dissection: preclinical cadaver feasibility study and proposed surgical technique. J Robot Surg 2011;5:279-82.

18. Richmon JD, Pattani KM, Benhidjeb T, et al. Transoral robotic-assisted thyroidectomy: a preclinical feasibility study in 2 cadavers. Head Neck 2011;33:330-3.

19. Chai YJ, Kim HY, Kim HK, et al. Comparative analysis of 2 robotic thyroidectomy procedures: Transoral versus bilateral axillo-breast approach. Head Neck 2018;40:886-92. 